\title{
Article
}

\section{Efficacy of using non-linear pedagogy to support attacking players' individual learning objectives in elite-youth football: A randomised cross-over trial}

Roberts, Simon J., Rudd, James R. and Reeves, Matthew

Available at http://clok.uclan.ac.uk/28384/

Roberts, Simon J., Rudd, James R. and Reeves, Matthew ORCID: 0000-00023903-2910 (2019) Efficacy of using non-linear pedagogy to support attacking players' individual learning objectives in elite-youth football: A randomised cross-over trial. Journal of Sports Sciences, 38 (11-12). pp. 1454-1464. ISSN 0264-0414

It is advisable to refer to the publisher's version if you intend to cite from the work. http://dx.doi.org/10.1080/02640414.2019.1609894

For more information about UCLan's research in this area go to http://www.uclan.ac.uk/researchgroups/ and search for <name of research Group>.

For information about Research generally at UCLan please go to http://www.uclan.ac.uk/research/

All outputs in CLoK are protected by Intellectual Property Rights law, including Copyright law. Copyright, IPR and Moral Rights for the works on this site are retained by the individual authors and/or other copyright owners. Terms and conditions for use of this material are defined in the policies page. 
Title:

Efficacy of using nonlinear pedagogy to support attacking players' individual learning objectives in elite-youth football: A randomised cross-over trial

Running Head:

Efficacy of nonlinear pedagogy in elite-youth football

Authors:

Institutions and departments:

Funding: No funding was received for this study

Correspondence:

Simon J. Roberts ${ }^{1} \&$ James R. Rudd ${ }^{1}$ Matthew J. Reeves ${ }^{2}$

Institutions and departments:

${ }^{1}$ School of Sport Studies, Leisure and Nutrition Liverpool John Moores University, IM Marsh Campus, Barkhill Road, Liverpool, UK.

${ }^{2}$ Institute of Coaching and Performance (ICaP), Faculty of Sport, Health and Wellbeing, University of Central Lancashire.

Funding: No funding was received for this study

Correspondence: Simon Roberts, Liverpool John Moores University, IM Marsh Campus, Liverpool, L17 6BD.

Email: s.roberts2@1jmu.ac.uk

Phone: +44 (0)151231 5426 
Title:

Efficacy of using nonlinear pedagogy to support attacking players' individual learning objectives in elite-youth football: A randomised cross-over trial Running Head:

Efficacy of nonlinear pedagogy in elite-youth football 


\begin{abstract}
The present study examined the efficacy of a coaching curriculum, based on nonlinear pedagogy, on improving attacking players' individual learning objectives (ILOs) in elite-youth football. Participants included 22 attacking players (i.e. centre-forwards, wide-players and attacking midfield players) from a professional football academy in England. The players were randomly appointed to both control (CON) and intervention (INT) periods following baseline measures. The INT (nonlinear) and CON (linear) periods were both designed to support the ILOs provided to each player as part of the elite player performance plan. The study adopted a randomised cross-over design and ILOs considered important for attacking players (i.e. strong foot finishing, weak foot finishing, 1-v-1 and decision making) were evaluated using the Loughborough Shooting Skill Test. The results showed significant differences for INT in 1-v$1(P<0.02)$ and decision making $(P<0.01)$. However, there were no significant differences for strong foot finishing, weak foot finishing or time taken. These results support nonlinear pedagogy in developing 1-v-1 game play and decision-making but not for technical shooting proficiency.
\end{abstract}

Keywords: Talent, dynamic systems theory, ecological psychology, team sports, players' development, skill acquisition, motor learning 


\section{Introduction}

In England and Wales, a professional football academy defined as an elite performance development environment, is where potentially talented youth players, aged between 8-18 years, are recruited with the aim of becoming professional footballers (Mills, Butt, Maynard \& Harwood, 2012). This highly-targeted approach, however, is not without its limitations, as evidence suggests that up to $90 \%$ of junior-elite footballers, admitted to an academy fail to achieve full professional status (Anderson \& Miller, 2012). In 2011 the Elite Player Performance Plan (EPPP; The Premier League, 2011), was introduced, in part, to help increase the number of home-grown players competing in the English Premier League and Football Leagues. In short, the EPPP separates player development into three distinct phases: foundation (under 9 to under 11), youth development (under 12 to under 16) and professional development (under 17 to under 23), and a player's developmental progress is monitored using the Performance Management Application (PMA) database (Premier League, 2011). Academies are audited as part of this process and records of coaching sessions, curriculum provision, and player ILOs are included as part of this quality assurance procedure. Specifically, player ILOs are intended to be the focus of a players' development over a six week period; they are, typically, decided upon by the age group lead coach, sometimes in conjunction with the player and in some instances including parents (Littlewood, Nesti \& Luthardt, 2018). The inception of the EPPP has resulted in an increase in accumulated coaching hours (i.e. from $\sim 3,760$ hours to $\sim 8,500$ hours) and academy coaches are encouraged to develop innovative curriculum design and practice sessions to maximise the learning opportunities from the increased time spent in training (Mitchell, Nesti, Richardson, Midgley, Eubank \& Littlewood, 2014; Tears, Chesterton \& Wijnbergen, 2018).

A learning approach that has gained considerable attention amongst advocates of dynamical systems theory and ecological psychology is nonlinear pedagogy (NP; Chow, 
2013). Empirical support for the application of dynamical systems theory is predominantly found in physical education pedagogy and motor-learning literature (Davids, Button, \& Bennett, 2008). In brief, NP is defined as the "application of the concepts and tools of nonlinear dynamics" (Chow et al. 2006, p.72) and includes a number of principles, such as representative learning design, the manipulation of relevant constraints (i.e. performer, task and environment), emphasis on 'task simplification' in practice designs, promotion of external focus of attention, and exploiting the functional role of variability. The net effect of these principles provide the performer with the autonomy to experiment and create solutions that best answer their individual needs within a given context. In a practice context, information is directly perceivable to be picked-up by individual learners to constrain their actions (Davids et al., 2008). Perception is, therefore, a process of searching for the 'specifying' information that can be used to guide movements and in turn, generate more information that can be used for movement control. Pedagogic features for the coach to consider include promoting selfdirected actions, providing learners with opportunities to develop appropriate perception action couplings (Renshaw et al., 2016). As such, perceptual-motor and tactical skill acquisition are promoted implicitly by the coach introducing dynamic training simulations that more accurately reflect the competitive demands of performance (Pinder, Davids, Renshaw, \& Araújo, 2011). Through the manipulation of task constraints (i.e., space, equipment, rules etc.) NP promotes an external focus of attention, thus challenging the learner to devise solutions to specific motor skills tasks. For instance, previous NP research has illustrated how changing the method of delivery for a batter in cricket, from a bowler to a bowling machine can result in significant changes in timing and co-ordination of a front foot defensive stroke (Renshaw, Oldham, Golds, \& Davids, 2007). The creation of coachable moments using NP to improve motor competence however requires the coach to possess an in-depth knowledge of movement (Chow, 2013) and whilst the relative benefits of NP have 
been discussed in school based settings (Chow \& Atencio, 2014) to date there is little empirical evidence of NP in professional football environments.

Due to the rapid, complex and unpredictable nature of the in-game environment, it is well established that talented youth players require a combination of perceptual, cognitive and motor skill proficiency (Rocca, Williams \& Ford, 2012; Savelsberg et al., 2010). As the principal aim of a football match is to score more goals than the opposition, technical attributes such as striking the ball, shooting speed, shooting accuracy and 1-v-1 skills are important considerations for strikers and players with attacking responsibilities (Coutinho et al., 2018; Radman et al, 2016). From a perceptual-cognitive perspective, attributes such as anticipation and decision making have been recently demonstrated as key features of a strikers'/attacking players' makeup in the eyes of talent experts (Roberts, et al., 2019). There is, however, some debate as to what pedagogy is most effective when working with youth professional footballers as part of a habitual training programme. For instance, a reductionist linear micro-practice designed to improve attacking players shooting accuracy may involve striking a ball from a stationary position around a mannequin or cone. This type of repetitious, blocked activity is based on breaking the motor skill down into smaller component parts to reduce attentional demands (Ford, Yates \& Williams, 2010). This partpractice activity where the player is working on an isolated technical skill and working unopposed is commonly referred to as training form (TF) activity. Previous results have indicated that TF activity was predominantly used in youth soccer training sessions when compared to game-context practices incorporated through either small-sided games or phases of play (Roca et al., 2012, Williams et al., 2012). Critics of this pedagogy however, argue that during competition shooting requires perceptual and cognitive components, such as ball position, positioning of teammates, distance from the goal and the position of the goalkeeper (Radman et al., 2016). Advocates of perceptual and cognitive learning suggest playing form 
(PF) as the type of activities similar to the game-context incorporated through either small sided games and phases-of-play that are opposition-based, designed to promote perceptualcognitive processes (i.e. Roca et al., 2012; Williams et al., 2012). Several authors (i.e. Roca et al., 2012; Williams et al., 2012) have suggested that practices representative of PF are beneficial to promote the development of tactical decision-making and anticipation. There is a dearth of studies which have examined NP in performance coaching domains and to our knowledge, this is the first study to examine the alignment of coaching practice to the ILOs of youth players at the professional phase of the EPPP. The primary aim of this study therefore was to examine the effects of two different pedagogies on the development of attacking player's performance skills in youth professional football.

\section{Methods}

Study design

The study was designed as a within subjects randomised cross-over trial. The study was performed in full compliance with the World Medical Association (Declaration of Helsinki) and was approved by the ethics committee of an Institutional Review Board in the United Kingdom. The nature and purpose of the study was communicated with all the participants and as the participants were under the age of consent, permission of parents or those with legal responsibility for the individual was obtained.

\section{Participants}

Twenty-two players from the youth academy of a professional English League club volunteered to take part in the study. The participants were randomly allocated to two testing INT (mean \pm SD: age, $16.4 \pm 0.4$ years; height, $1.70 \pm 0.03 \mathrm{~m}$; body mass, $72.8 \pm 7.7 \mathrm{~kg} ; \dot{\mathrm{VO}}_{2}$ max; $61.6 \pm 4.56 \mathrm{ml} \cdot \mathrm{kg}^{-1} \cdot \mathrm{min}^{-1}$ ) and CON (mean \pm SD: age, $16.1 \pm 0.2$ years; height, $1.74 \pm$ $0.05 \mathrm{~m}$; body mass, $73.5 \pm 5.5 \mathrm{~kg}$; $\dot{\mathrm{VO}}_{2}{ }^{\max } ; 62.4 \pm 4.26 \mathrm{ml} \cdot \mathrm{kg}^{-1} \cdot \mathrm{min}^{-1}$ ) periods using a 
computer-based algorithm by an independent researcher not involved with the current study. According to the clubs roster the players in INT were categorised into the following attacking outfield positions: strikers $(n=5)$, wide-players $(n=2)$, attacking midfielders $(n=4)$. The players in $\mathrm{CON}$ were categorised into the following attacking outfield positions and included the following: strikers $(n=4)$, wide-players $(n=3)$, and attacking midfielders $(n=5)$. All the players had a minimum of two years training history of 3-6 days per week. All participants were equipped with their standard training uniform and footwear. Size 5, Mitre Delta EFL footballs were used for all the testing protocols.

Two full-time professional coaches at the academy volunteered to participate in the study. Coach A was a male, ex-professional footballer with 14 years' playing experience, he held the Union of European Football Association (UEFA) 'B' licence and was in the process of working towards the completion of the UEFA 'A' licence. He had also completed a postgraduate qualification in sport coaching where he successfully completed a pedagogy module which included the theoretical and practical features of NP. He had worked in the academy for three years in various coaching roles and delivered the NP intervention. Coach B was also an ex-professional player and held the UEFA 'A' licence coaching qualification.

Coach B had worked in the academy for eight years and he delivered the linear pedagogy (LP) coaching programme. Due to logistical reasons, it was not possible to blind the researchers, coaches, or players prior to the randomisation process. All participants provided full assent and consent to take part in the study and were notified that they could withdraw from the study at any time. The study was also approved by the academy director at the club.

\section{Intervention period}

The intervention replaced the traditional 'training form' activity that was structured around a LP approach. The intervention was included as part of a habitual 'in season' training 
programme (i.e., one 60-minute 2 x 30-minute) training sessions twice per week for four weeks. All the sessions were scheduled around 'pitch-based' training sessions and competitive match-play (Enright et al., 2018). The intervention was delivered on nonconsecutive days at the beginning of a 'pitch-based' technical/tactical training session while other members of the squad were involved in regular training activities conducted by the head coach (Coutinho et al., 2018). The learning objectives for the INT period were to improve a range of attacking player's ILOs with the integration of technical and tactical instruction using NP. During the INT period Coach A was required to adhere to an NP approach firstly by creating a representative learning design and promoting the concept of emergence through self-directed actions to develop appropriate perception - action couplings (Renshaw et al. 2016).

During the session a key role of the coach was to manipulate task constraints with the aim of creating boundaries in which movement possibilities are afforded to the players to promote intrinsic self-organisation tendencies that are indicative within a performance context relevant for attacking players. Common task constraints were modification of rules, manipulating player positions on the pitch, or increasing or decreasing the number of players involved in the practice (Passos, 2008). A key activity of the coach was to refine activities (i.e. task simplification) to enable players to develop and maintain strong functional couplings of information and movement during learning this was achieved through emphasis of the coach using integrated technical-tactical practices. The coach also encouraged players to focus on movement outcome rather than the movement form, this emphasised learners to be problem solvers and come up with innovative functional movement solutions during exploratory practice. Finally, the coach was taught to appreciate the role of variability and utilise it to challenge learners to explore different movement solutions. Throughout the 
intervention the coach was told they had to achieve ILOs by encouraging dynamic learning through free exploration (Renshaw et al., 2010).

\section{Control period}

Participants in the CON period received the same number of sessions consecutively, but these were delivered using LP. Linear pedagogy was considered to be a transmission-based practice, based on information-processing theory, where the coach acted as the expert, leading participants to a series of pre-determined outcomes (Vinson et al., 2016). For instance, a coach adopting LP would typically create a controlled, predictable learning environment by using high volumes of instruction, demonstration, and the explanation of an optimal movement pattern. The CON period was delivered by Coach B and he was instructed to deliver his sessions using the same approach from baseline and after the intervention. In the CON, the same participant received LP over the same period. Therefore, a participant who initially received the INT participated in the activities of the CON period group one month later (Figure 1). Both the NP and LP coaching sessions were scheduled around other training requirements such as physical conditioning, competitive match-play, education days, and rest days. 


\section{Coach intervention training and analysis}

Prior to the intervention, Coach A met with the lead author to discuss principles of NP and its theoretical underpinning of ecological dynamics, this allowed for coach and researcher to develop appropriate player ILOs and avoid training task decomposition and the isolation of movement skills (Davids, Button \& Bennett, 2007). Discussions centered around coupling essential attacking technical skills (i.e. shooting) with decision-making opportunities (affordances) with sufficient variation, to ensure it was representative of the demands of a performance environment. The challenge for the coach was to ensure participants were exposed to 'repetitive' but constantly adapting situations that afforded a variety of movement solutions (Renshaw et al., 2010). To help Coach A in the planning and design of the coaching curriculum and create a range of task constraints, Epstein's TARGET framework was adopted: task (activity design), authority (location of decision making), recognition (use of praise), grouping (selection of group size), evaluation (assessment criteria) and time (pace of instruction and learning) (Epstein, 1998). Here the coaches' aim was to create a positive, representative learning environment, that required players to be externally focused and to self-regulate, rather than rely on the coach for movement solutions. Prior to baseline Coach A designed and delivered 3 x 45-minute, NP coaching sessions to an age group not involved in this study.

The NP sessions were observed and recorded by the research team and analysed by the research team using a modified version of the System for Observing the Teaching of Games in Physical Education (SOGT-PE, Roberts \& Fairclough, 2012). Modifications focused solely on terminology, where terms such as 'pupil' were substituted for 'player' and 'teacher' for 'coach'. A detailed description of the validation procedure for SOTG-PE is provided elsewhere (e.g. Roberts \& Fairclough, 2012). In brief, SOTG-PE allows trained observers to simultaneously record and capture the proportion of session time participants spend in a 
range of activity types (i.e. inactive, motor response), the session contexts (e.g. warm-up, technical practice, modified game) and the level of coach interaction (i.e. verbal technical behavior, non-verbal tactical). For a full list of behavioral codes and definitions please refer to Figure 2. Coding for SOTG-PE occurs continuously and consecutively in 20-second intervals throughout the observed coaching session. In the validation study, SOTG-PE was reported to be reliable in both physical education and sport coaching environments, and was used recently to capture an NP intervention by a UEFA ' $\mathrm{B}$ ' licensed coach working at a football Centre of Excellence in the West Midlands of England (Vinson et al, 2016).

$$
\text { [***Figure } 2 \text { Near Here***] }
$$

\section{Fidelity of INT and CON periods}

In total, 16 coaching sessions ( $n=8 \mathrm{INT} ; n=8 \mathrm{CON})$ were filmed using a fixed, mounted camera (Sony HDV HVR-Z5), positioned on a viewing gantry that overlooked the training and coaching area to assess fidelity of the coaching pedagogy (Miller et al., 2017). The video camera was also connected to a wireless microphone system (Sennheiser ew 100 ENG G3, Germany) which both coaches wore on the lapel of their training uniform. This enabled the simultaneous capture of voice and player performance data. SOTG-PE observations were completed using the "Tagging" module within Dartfish 6 (Fribourg, Switzerland) on a Samsung Galaxy $\bigodot$ tablet once the coaching session had ended. At each record interval the observer pressed a relevant button on the tagging panel that was configured to the SOTG-PE instrument. The tagging panel was configured to ensure it did not create multiple events on the timeline. Systematic observations were conducted by trained members of the research team (McKenzie \& van der Mars, 2015). The observers received training in the use of the observation instrument from the lead author using video footage captured during the SOTGPE validation study. Inter-observer reliability was established after observing two 20-minute coaching sessions that was not part of the investigation. Agreement levels using Cohen's 
kappa was $>0.89$ and a percentage agreement above $92 \%$ was recorded which is considered reliable for systematic observation studies (Brewer \& Jones, 2006).

Outcome measures, procedure, tasks and equipment

Loughborough Shooting Skill Test (LSST): The LSST developed by Ali et al (2007) is considered a valid and reliable test for measuring shooting for both stronger and weaker foots, 1-v-1 proficiency and decision-making. All testing was completed at a professional football academy located in England on an outdoor grass pitch $(100.5 \mathrm{~m} \times 64.0 \mathrm{~m})$. Prior to completing the LSST players participated in a standardised $\sim 20$-minute warm-up based on low-intensity running, ball possession and dynamic stretching exercises. The warm up was delivered by one of the academy sport scientists. At baseline both INT and CON completed the LSST to assess shooting accuracy for both stronger and weaker foot, 1-v-1 proficiency, decision-making, and time taken to complete the test. In order to reduce trial order and learning effects each player performed two practice trials with each leg before testing.

The boundary lines for the test were marked on the grass pitch by standard cones $2 \mathrm{~m}$ apart. A "shooting zone" measuring $8.5 \mathrm{~m}$ x $8.5 \mathrm{~m}$ was marked with the nearest line $16.5 \mathrm{~m}$ from the goal line. Four traffic cones were placed at the corner of the shooting zone and a gymnasium bench was placed at the back of square to act as a rebound board (see Figure 3). A full size, freestanding stadium box football goal $(2.44 \mathrm{~m} \times 7.32 \mathrm{~m})$ was divided into various scoring zones and was marked using luminous green ( $5 \mathrm{~cm}$ width) tape. In the LSST validation test Ali et al (2007) used a static plywood goalkeeper to increase ecological validity of the test. In our test we placed a high visibility fluorescent yellow mannequin (FORZA, UK, $1.83 \mathrm{~m} \times 0.60 \mathrm{~m}$ ) in the goal to replicate the role of the goalkeeper. To create a decision-making component the position of the mannequin was adjusted when the participant had his back to goal and we graded the decision the participant made as either (1) appropriate 
or (0) inappropriate. In addition, to measure 1-v-1 proficiency we modified the LSST slightly and included a defender who was positioned adjacent to the goalpost. The defender became 'active' when the participant touched the ball and was instructed to sprint towards the ball carrier. Successful 1-v-1 proficiency were considered if the player maintained possession, beat the defender and executed a shot at goal.

\section{***[Figure 3 near here]***}

The LSST was performed according to the procedures suggested by Ali et al (2007). In brief, the test begins with the ball being placed in the marked circle in the centre of the shooting zone. The primary investigator was located at position " $\mathrm{A}$ " and the academy coach at location "B" in Figure 2. The primary investigator was responsible for ensuring the shot was taken within the shooting area and for recording if any points were scored. The academy coach was responsible for timing the participants movement and for moving the mannequin to the appropriate position (i.e. left, centre or right of the goal). To minimise inter-rater reliability the same two investigators conducted all the LSST testing (Enright et al, 2018). Participants were required to run as fast as possible to the cone as directed by the coach, touch the top of it, and then return the ball in the square. After executing a rebound pass off the bench, the player controlled the ball (if necessary), turned, and shot at goal. The participant was then required to sprint between two cones positioned $5.5 \mathrm{~m}$ away from and directly in front of the goal. Each participant performed a single trial of 10 shots, with a rest period of 60 seconds between each sequence. As players' ILOs included weak foot finishing, five shots were performed with the right foot and five shots with the left. The overall performance score was the mean total of the cumulative points accrued from shots on target.

\section{Data analysis}


The distribution of data and homogeneity of variance was examined using Shapiro-Wilk and Levene tests respectively. As data were non-normally distributed baseline comparisons between INT and CON were conducted with Mann-Whitney U tests. Being unsure of the normality of the distribution, the values before and after the intervention within the group were examined by the Wilcoxon signed-rank test. Descriptive statistics of player characteristics for both INT and CON (mean + standard deviation SD), were also computed. Coach systematic observation data were cross-tabulated and analysed in the form of frequency counts and percentages. Non-parametric Kruskal-Wallis tests were conducted between the player activity, session context and coach interaction variables. Spearman's rank order correlations were conducted to examine relationships between player activity, session context and coach interaction. Statistical analyses were performed using PASW Statistics 21 (SPSS Inc, Chicago, IL) software and alpha levels were set at $P<0.05$.

\section{Results}

Twenty-two players from a professional football academy in England volunteered to participate in the study. One player was excluded mid-way through the study due to an injury sustained during formal competition (Figure 1). There were no significant differences between CON and INT groups at baseline. At baseline, the primary outcomes of the LSST also indicated no significant differences between strong foot finishing, weak foot finishing, 1-v-1, decision making, or time taken (Table 1).

\section{LSST performance}

Both INT and CON marginally increased their mean shooting scores from baseline but MannWhitney U-tests revealed no significant differences between shooting with both stronger or weaker foot when comparing the INT and CON periods. The results of the comparison between INT and CON revealed a significant difference in 1-v-1 when comparing the intervention and control periods $(p<.002)$. The Mann-Whitney U-test revealed significant differences in 
decision-making scores before and after intervention $(p<.001)$. There were, however, no significant differences in time taken to complete the test.

\section{INT and CON coach observation}

A total of 16 coaching sessions were observed resulting in 1,024 minutes of overall coded video footage. On average each coaching session lasted for $(64.2 \pm 4.4 \mathrm{~min})$ for INT and $(62.1 \pm 2.4 \mathrm{~min})$ for $\mathrm{CON}$ periods respectively. Each coach was observed on eight separate occasions and a summary of the crosstabulation for both Coach A and Coach B are presented in Tables 2 and 3.

\section{Session context}

Coach A's coaching practice focussed on the use of Applied Skill Practice (36.8\%), Modified Game (22.4\%) and Small-Sided Games (16.3\%). The remaining time was spent in General Management activities (24.5\%) which generally involved setting up task constraints and asking the participants questions to generate some self-analysis. Coach A did not deliver any Technical Skill Practices. The emphasis on applied NP game-related activities also resulted in lower levels of Inactivity (24.5\%) when compared to the CON group (37.3\%) with high volumes of Locomotor (39.1\%) and Motor/Locomotor (35.2\%) activity. Coach B who delivered LP spent most of the coaching time in Technical Skill Practice (52.6\%), General Management (20.9\%), Small-Sided Games (18.3\%) and Applied Skill Practice (8.2\%). Coach B did not use any Modified Games. The high volumes of Technical Skill Practice resulted in the players standing around and waiting their turn which accounted for the high volumes of inactivity (35.5\%). Both Coach A and Coach B spent most time Verbally Promoting a Technical Behaviour (40.4\% and 57.1\%) respectively. Coach A, however, spent substantially more time Verbally Promoting Tactical Behaviour (24\% and $12.7 \%)$ respectively. Across the INT and CON periods there were significant differences in the time 
spent Inactive $\left(\chi^{2}(1) 18.58, p<.002\right)$ Technical Skill Practice $\left(\chi^{2}(1) 12.18, p<.001\right)$ and Modified Game $\left(\chi^{2}(1) 14.43, p<.001\right)$. The players in the INT period spent significantly longer periods of time in Applied Skill Practice $\left(\chi^{2}(1) 18.43, p<.001\right)$ and Modified Game than CON periods.

Player activity, session context and coach interaction relationships

Spearman's rank order correlations revealed a significant positive relationship between participant Inactivity and General Management in $(r=0.58, p<.001)$ and Skill Practice $(r=$ $0.56, p<.001$.) There was also a significant positive association between Technical Skill Practice and Motor/Locomotion $(r=0.49, p<.005)$. A significant positive relationship was found between Locomotor Response and Applied Skill Practice $(r=0.53, p<.005)$ and Modified Game $(r=0.51, p<.005)$. A significant inverse association was observed between Verbally Promoting Tactical Behaviour and Technical Skill Practice $(r=0 .-64, p<.002)$.

\section{Discussion}

The aim of this research was to examine the efficacy of a coaching programme, based on NP, on developing attacking players' ILOs and session involvement with elite-youth football players. Participants in the INT periods performed significantly better on the LSST in 1-v-1 execution and decision-making than CON. Better performances in strong foot finishing, weak foot finishing and time taken were observed across both INT and CON periods from baseline, however these were not significant. The improvement in the decision-making component of the LSST suggest the manipulation of different task conditions enabled the players to adapt to the variability of practice and perform better on this aspect of the test (Chow et al., 2009). For instance, a feature of the NP intervention was the use of applied technical-tactical skill practice contexts which contained numerical attacking superiority (i.e., 2 vs. 1, 3 vs. 2, 4 vs. 3 etc.). Previous NP research (i.e., Pizarro et al., 2018) reported comparable decision-making 
improvements, albeit in youth futsal players when exposed to similar reductions in defensive pressure, however, in our study it is unclear whether the decision-making improvement was due to the manipulation of the task or the level of pressure applied by the opposition players.

The NP curriculum is a player-centred approach that required the coach to have an understanding of how interacting constraints can be manipulated in a nuanced way to shape the acquisition of movement skills that are advantageous in attacking situations. It has been highlighted that a challenge for coaches delivering NP is they need to have good content knowledge of the game in order to meaningfully manipulate appropriate constraints to support effective exploration by the player (Renshaw \& Chow, 2018). This study has found that coaches in a professional youth football academy with extensive footballing knowledge are capable of employing principles of NP and that this can lead to greater learning outcomes than coaches with similar expertise and experience of teaching a LP method.

The NP curriculum does not however appear to be any more effective than LP in developing technical skills such as shooting on either stronger or weaker foot. This finding is in line with previous research (Chow et al., 2009). A similar finding was reported by Pizarro et al., (2018) in their study of youth soccer in the U12 age category. Using the Game Performance Evaluation Tool, they reported how NP improved decision-making and the execution of passes during small-sided games but not for dribbling. In the current study the CON periods which were delivered using LP also did not significantly improve the levels of shooting accuracy. A critique for adoption of NP is the time required to observe skill improvement through a method that encourages exploratory behaviours. This study does not support this assertion, and whilst Coach A did not explicitly focus on technical aspects of skill development as was the case for Coach B, there was little difference in skill learning between the two groups. As such in a high pressured environment such as a professional youth football, coaches should not feel pressured to 'accelerate learning' by being more prescriptive and over-using instructions to satisfy 
targets, as this may limit learning opportunities in other domains and may not lead to improved technical proficiency. The lack of improvement in shooting proficiency may also be a consequence of the short duration of the intervention and this should be taken into consideration when interpreting these results.

In the observed coaching sessions participants in the CON periods spent significant amounts of time Inactive. This was when the coach was engaged in General Management and Technical Skill Practice, which involved high volumes of isolated demonstrations and coach instruction about appropriate task requirements and movement patterns (Partington, Cushion, \& Harvey, 2013). Conversely relatively low periods of Inactivity were recorded during the INT periods when the coach spent time in Applied Skill Practice and Modified Game. In both INT and CON periods both coaches spent most time Verbally Promoting Technical Behaviour, however, Coach B was observed to spend considerably more time engaged in this behaviour than Coach A. The qualitative observations of the footage suggest both coaches spent high volumes of this time prioritising feedback. Coach A for instance was observed to spend periods of time requesting feedback (i.e. asking questions) from the participants following mistakes that occurred during a practice related task. Coach A was observed asking questions, but only to promote external focus of attention and was not corrective. In contrast, Coach B provided feedback on specific performance outcomes and knowledge of results (i.e. shooting accuracy). Although SOTG-PE is not sensitive enough to capture the volume of coach behaviours (i.e. feedback, instruction etc.) the high volume of time spent providing feedback with this age group is similar to Partington, Cushion and Harvey (2013) and may be indicative of their stage in EPPP phase.

Strengths of this study include an appropriate study design for measuring the effect of a new treatment (i.e. NP coaching curriculum) within a small sample, as the outcomes were measured in the same participants. Second, due to the demanding and competitive schedule of the 
academy environment conducting applied interventions 'within season' is considered a challenge (Enright et al., 2018). This study was conducted around the teams habitual training practice without the need to remove training activities from the players' weekly schedule.

\section{Practical implications}

Whilst the present study provides support for the use of NP in professional training environments, future research should consider evaluating NP with a larger number of participants, with teams of different age categories conducted over an extended period of time. The cross-over design of this study enabled both sets of players to receive the NP treatment and a recommendation for future applied work in this area would be to consider similar research designs.

\section{Limitations}

This study however contains some limitations which also need to be acknowledged. First, this study cannot mitigate for the potential of a 'learning effect' as it was not possible to include a 'wash-out' period. Second, the players' previous experiences of NP were not captured during the baseline stage of the study, it is therefore unclear how receptive players were to the treatment conditions. This may have resulted in better performances from the first phase of the study and this needs to be considered when interpreting these results. Third, the intervention period was relatively short and the sample size could be considered as small (Hopkins et al., 2001). Finally, the LSST does not replicate a match situation, future research directions surrounding NP in elite-youth football environments should consider more ecological measures of in-game performance, such as small-sided games.

\section{Conclusion}

To our knowledge, this is the first study to examine NP within a performance-based environment in elite-youth football. The central findings of this study provide some support 
for NP in developing attacking game behaviour and more accurate decision-making but not for technical ability. This study provides evidence that the application of NP in youth professional football is feasible and will support players development, however, it must be stressed that this is an exploratory first step, and we welcome further ecological work in this area to elucidate our claims.

\section{Disclosure of interest}

The authors report no conflict of interest. 


\section{Acknowledgements}

We would like to express our gratitude to all of the players and coaches who participated in this study. We also acknowledge the postgraduate students who acted as members of the research team, for all their efforts in data capture. 


\section{References}

Ali, A., Williams, C., Hulse, M., Strudwick, A., Reddin, J., Howarth, L., ... McGregor, S. (2007). Reliability and validity of two tests of soccer skill. Journal of Sports Sciences, 25(13), 1461-1470. DOI: 10.1080/02640410601150470

Anderson, G., \& Miller, R. (2012). The academy system in English professional football. Liverpool. Retrieved from http://bnb.data.bl.uk/id/resource/015887187

Brewer, C. J., \& Jones, R. L. (2002). A Five-Stage Process for Establishing Contextually Valid Systematic Observation Instruments: The Case of Rugby Union. The Sport Psychologist, 16(2), 138-159. DOI: 10.1123/tsp.16.2.138

Capio, C. M., Poolton, J. M., Sit, C. H. P., Holmstrom, M., \& Masters, R. S. W. (2013). Reducing errors benefits the field-based learning of a fundamental movement skill in children. Scandinavian Journal of Medicine \& Science in Sports, 23(2), 181-188. DOI: 10.1111/j.1600-0838.2011.01368.x

Chow, J. Y. (2013). Nonlinear Learning Underpinning Pedagogy: Evidence, Challenges, and Implications. Quest, 65(4), 469-484. DOI: 10.1080/00336297.2013.807746

Chow J.Y., \& Atencio, M. (2014). Complex and nonlinear pedagogy and the implications for physical education. Sport, Education and Society 17;19(8):1034-54. DOI: https://doi.org/10.1080/13573322.2012.728528

Chow, J. Y., Davids, K., Button, C., Renshaw, I., Shuttleworth, R., \& Uehara, L. A. (2009) Nonlinear pedagogy: implications for teaching games for understanding (TGfU). In T. Hopper, J. Butler, \& B. Storey (Eds.), TGfU: Simply Good Pedagogy: Understanding a Complex Challenge (pp. 131-143). Ottawa: Ottawa Physical Health Education Association.

Chow, J. Y., Davids, K., Button, C., Shuttleworth, R., Renshaw, I., \& Araújo, D. (2006). Nonlinear pedagogy: a constraints-led framework for understanding emergence of game play and movement skills. Nonlinear Dynamics, Psychology, and Life Sciences, 10(1), $71-103$.

Coutinho, D., Santos, S., Gonçalves, B., Travassos, B., Wong, D. P., Schöllhorn, W., \& Sampaio, J. (2018c). The effects of an enrichment training program for youth football attackers. PLoS One, 13(6), e0199008.

Davids, K., Button, C., \& Bennett, S. (2007). Dynamics of skill acquisition: A constraints-led approach. Champaign, IL: Human Kinetics.

Enright, K., Morton, J., Iga, J., Lothian, D., Roberts, S., \& Drust, B. (2018). Reliability of "in-season" fitness assessments in youth elite soccer players: a working model for practitioners and coaches. Science and Medicine in Football, 2(3), 177-183. DOI: $10.1080 / 24733938.2017 .1411603$ 
Epstein, J. (1998). Family structures and student motivation: A developmental perspective. In C. Ames \& R. Ames (Eds.), Research on motivation in education (pp. 259-295). New York, NY: Academic Press.

Ford, P. R., Yates, I., \& Williams, A. M. (2010). An analysis of practice activities and instructional behaviours used by youth soccer coaches during practice: Exploring the link between science and application. Journal of Sports Sciences, 28(5), 483-495. DOI: $10.1080 / 02640410903582750$

Hopkins, W. G., Schabort, E. J., \& Hawley, J. A. (2001). Reliability of Power in Physical Performance Tests. Sports Medicine, 31(3), 211-234. DOI: 10.2165/00007256200131030-00005

Littlewood, M., Nesti, M., \& Luthardt, C. (2018). Delivering applied sport psychology support in professional football academies. In W. Gregson \& M. Littlewood (Eds.), Science in Soccer: Translating Theory into Practice (pp. 16-37). London: Bloomsbury Sport.

McKenzie, T. L., \& van der Mars, H. (2015). Top 10 Research Questions Related to Assessing Physical Activity and Its Contexts Using Systematic Observation. Research Quarterly for Exercise and Sport, 86(1), 13-29. DOI: 10.1080/02701367.2015.991264

Miller, A., Harvey, S., Morley, D., Nemes, R., Janes, M., \& Eather, N. (2017). Exposing athletes to playing form activity: outcomes of a randomised control trial among community netball teams using a game-centred approach. Journal of Sports Sciences, 35(18), 1846-1857. DOI: 10.1080/02640414.2016.1240371

Mills, A., Butt, J., Maynard, I., \& Harwood, C. (2012). Identifying factors perceived to influence the development of elite youth football academy players. Journal of Sports Sciences, 30(15), 1593-1604. DOI: 10.1080/02640414.2012.710753

Mitchell, T. O., Nesti, M., Richardson, D., Midgley, A. W., Eubank, M., \& Littlewood, M. (2014). Exploring athletic identity in elite-level English youth football: a cross-sectional approach. Journal of Sports Sciences, 32(13), 1294-1299. DOI: $10.1080 / 02640414.2014 .898855$

Partington, M., \& Cushion, C. (2013). An investigation of the practice activities and coaching behaviors of professional top-level youth soccer coaches. Scandinavian Journal of Medicine \& Science in Sports, 23(3), 374-382. DOI: 10.1111/j.1600-0838.2011.01383.x

Passos, P., Araújo, D., Davids, K., \& Shuttleworth, R. (2008). Manipulating Constraints to Train Decision Making in Rugby Union. International Journal of Sports Science \& Coaching, 3(1), 125-140. DOI: 10.1260/174795408784089432

Pinder, R. A., Davids, K., Renshaw, I., \& Araújo, D. (2011). Representative Learning Design and Functionality of Research and Practice in Sport. Journal of Sport and Exercise Psychology, 33(1), 146-155. DOI: 10.1123/jsep.33.1.146

Pizarro, A. P., Del Villar, F., Pizarro, D., \& Moreno, A. (2018). The Impact of Nonlinear Pedagogy on Decision-Making and Execution in Youth Soccer Players According to 
Game Actions. Journal of Human Kinetics, 62(1), 185-198. DOI: 10.1515/hukin-20170169

Premier League. (2011). Elite player performance plan. London.

Radman, I., Wessner, B., Bachl, N., Ruzic, L., Hackl, M., Baca, A., \& Markovic, G. (2016). Reliability and Discriminative Ability of a New Method for Soccer Kicking Evaluation. PLOS ONE, 11(1), e0147998. DOI: 10.1371/journal.pone.0147998

Renshaw, I., \& Chow, J. Y. (2018). A constraints-led approach to sport and physical education pedagogy. Physical Education and Sport Pedagogy. DOI: 10.1080/17408989.2018.1552676.

Renshaw, I., Chow, J. Y., Davids, K., \& Hammond, J. (2010). A constraints-led perspective to understanding skill acquisition and game play: a basis for integration of motor learning theory and physical education praxis? Physical Education \& Sport Pedagogy, 15(2), 117-137. DOI: 10.1080/17408980902791586

Renshaw, I., Oldham, A. R. H., Davids, K., \& Golds, T. (2007). Changing ecological constraints of practice alters coordination of dynamic interceptive actions. European Journal of Sport Science, 7(3), 157-167. DOI: 10.1080/17461390701643026

Roberts, S., \& Fairclough, S. (2012). A five-stage process for the development and validation of a systematic observation instrument: The system for observing the teaching of games in physical education (SOTG-PE). European Physical Education Review, 18(1), 97-113. DOI: $10.1177 / 1356336 \mathrm{X} 11430653$

Roberts, S. J., McRobert, A., Lewis, C., \& Reeves, M. J. (in press). Establishing consensus of position-specific predictors for youth soccer in England. Science \& Medicine in Football.

Roca, A., Williams, A. M., \& Ford, P. R. (2012). Developmental activities and the acquisition of superior anticipation and decision making in soccer players. Journal of Sports Sciences, 30(15), 1643-1652. DOI: 10.1080/02640414.2012.701761

Roca, A., Williams, A. M., \& Ford, P. R. (2012). Developmental activities and the acquisition of superior anticipation and decision making in soccer players. Journal of Sports Sciences, 30(15), 1643-1652. DOI: 10.1080/02640414.2012.701761

Savelsbergh, G. J. P., Haans, S. H. A., Kooijman, M. K., \& van Kampen, P. M. (2010). A method to identify talent: Visual search and locomotion behavior in young football players. Human Movement Science, 29(5), 764-776. DOI:

10.1016/j.humov.2010.05.003

Tears, C., Chesterton, P., \& Wijnbergen, M. (2018). The elite player performance plan: the impact of a new national youth development strategy on injury characteristics in a premier league football academy. Journal of Sports Sciences, 36(19), 2181-2188. DOI: 10.1080/02640414.2018.1443746 
Vinson, D., Brady, A., Moreland, B., \& Judge, N. (2016). Exploring coach behaviours, session contexts and key stakeholder perceptions of non-linear coaching approaches in youth sport. International Journal of Sports Science \& Coaching, 11(1), 54-68. DOI: $10.1177 / 1747954115624824$

Williams, A. M., Ward, P., Bell-Walker, J., \& Ford, P. R. (2012). Perceptual-cognitive expertise, practice history profiles and recall performance in soccer. British Journal of Psychology, 103(3), 393-411. DOI: 10.1111/j.2044-8295.2011.02081.x 